\title{
Predictors of Access to Mental Health Care Services Among Persons with Severe Mental Disorders: A Community-Based Study from Rural South India
}

Vijaya Raghavan ${ }^{1}$, Aishwarya Gonzalez Cherubal ${ }^{2}$, Sujit John $^{3}$, Kotteswara Rao ${ }^{4}$, R Padmavati ${ }^{5}$, R Thara ${ }^{6}$

\begin{abstract}
Background: Various factors are associated with access to care among patients with severe mental disorders (SMD). The aim of this study was to identify the predictors of access to care among patients with SMD in rural south India.
\end{abstract}

Methods: The study was conducted in Pudukkottai district of Tamil Nadu, India. After screening and confirmation of SMD by community level workers and trained mental health workers, participants were classified as those who have at some time sought treatment and those who have never accessed mental health care services.

Results: Among 422 participants with SMD, 74\% had at some point in time accessed mental health care services. Logistic regression showed education asthe predictor of access to mental health care services among patients with severe mental disorders.

Conclusion: Improving education and awareness on the mental illness and its treatment options will help the patients with mental illness to seek care early leading to favorable outcomes.

Keywords: severe mental disorders, schizophrenia, community, access to care, India, education

Running Title: Predictors of access to care in SMD in south India

Address for Correspondence: Vijaya Raghavan, Consultant Psychiatrist, Schizophrenia Research Foundation, R/7A, North Main Road, Anna Nagar West
Extension, Chennai - 600101, Tamil Nadu, India.E mail: vijayaraghavan@scarfindia.org

How to Cite this Article: Vijaya Raghavan, Cherubal AG, John S, Rao K, Padmavati R, Thara R. Predictors of access to mental health care services among persons with severe mental disorders: A community-based study from rural South India. Indian Journal of Mental Health and NeuroSciences.2020;4(1): pp 34-40

\section{INTRODUCTION}

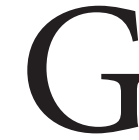
lobally, the mental health gap is enormous, with many who need treatment not seeking it. ${ }^{1}$ The delay in treatment and the consequent longer duration of untreated illness is associated with higher symptom severity and poorer outcomes for both severe and common mental disorders. ${ }^{1,2,3}$ Untreated psychosis may result in altered brain structure and neurodegenerative progression, damage which can be prevented or minimized through early intervention. ${ }^{3,4}$ Further, treatment-naive patients with schizophrenia have a higher prevalence of homelessness, poor longterm mental status, and more psychotic symptoms than treated patients. ${ }^{5,6,7}$

Explanatory models, gender, age, education level, perceived stigma and discrimination, cultural norms and practices have all been known to affect help seeking. So are some enabling factors like social support, awareness about mental illnesses and mental health services; as well as perceived and the actual need for services. ${ }^{8,9,10,11}$ However, no sociodemographic factor has emerged consistently across studies.

\footnotetext{
${ }^{1}$ Consultant Psychiatrist-Research; ${ }^{2}$ Research Intern; ${ }^{3}$ Psychologist, ${ }^{4}$ Psychiatric Social Worker; ${ }^{5}$ Director; ${ }^{6}$ Vice Chairman, Schizophrenia Research Foundation, R/7A, North Main Road, Anna Nagar West Extension, Chennai, India.
} 
A substantial number of patients with schizophrenia remain untreatedinlow-andmiddle-incomecountries. ${ }^{5,12}$ India is no exception, with a vast majority of people not receiving access to care. A door- to- door survey from South India reported that nearly one-third of patients with severe mental disorders remain untreated despite the proximity to and affordability of the facilities. ${ }^{12}$ One of the main reasons for a delay in the initiation of effective treatment is stigma and discrimination. According to Koschorke et al., ${ }^{13}$ caregivers' stigma is associated with higher levels of positive symptoms and higher disability level. In India, barriers to access to care include lack of awareness, cultural issues, supernatural and religious beliefs. Despite the increase in treatmentseeking behaviour, many low and middle-income countries still report people receiving macro-religious practices for mental illness. Several reasons like lack of awareness, ignorance, stigma, and belief are attributed to reduced medical treatment amongst people with mental illness. ${ }^{14}$ Studies from India have observed that people attributed mental illness to some form of punishment from God, sadness or unhappiness, air pollution, or excessive or constrained sexual desire and sought help from faith healers and religious leaders. ${ }^{15,16}$ Research has shown that these layman beliefs are most likely attributed to people who have not attained a high level of education and lack awareness. ${ }^{17}$ However, better recovery and reduced relapse have also been associated with religious beliefs in people with schizophrenia. ${ }^{18}$

This study was a part of a survey conducted to screen for mental disorders in the Pudukkottai district of the state of Tamil Nadu in south India. The aim of this study was to identify the predictors of accessing mental health care services among patients with severe mental disorders (SMD) living in the rural community in Tamil Nadu, India, using a cross-sectional research design.

\section{METHODS}

Survey

The survey set out to identify the number of persons in need of mental health services, determine their access pattern, and subsequently estimate the reach of the program-based services. As the program was focused on delivering care to individuals with SMD, the survey also focused on this group.

The survey questionnaire was designed based on the Indian Psychiatric Survey Schedule(IPSS) (psychoses section) and the General Screening Questionnaire
(GSQ) of the Family Interview for Genetic Studies (FIGS). ${ }^{19,20}$ It was translated into Tamil and field-tested. The questionnaire was formatted to fit into a two-stage survey process - the first stage was completed by a Field Survey Staff (FSS) and the second stage by a trained mental health professional (MHP).

The survey started in August 2010 and was completed in September 2011. The process adopted was initiated by a meeting with the local village leaders to inform them about the survey and enlist their support; (2) Following this, a door-to-door survey was conducted wherein a key informant was identified for each family with whom the survey questionnaire was then completed; (3) If an affected individual was identified by the FSS, the information was passed on to the MHPs who verified the details and then completed the assessments.

\section{Site description}

The survey was conducted in two taluks of Pudukkottai, a relatively underdeveloped and lessurbanized districts in Tamil Nadu. They were Thirumayam and Gandarvakottai Taluks which were the study sites. Thirumayam comprises of 80 revenue villages,one town, 5 primary Health Centres (PHC), and 27 sub-centres under the public health system (PHS). In comparison, Gandarvakottai comprises of 37 revenue villages, 2 PHCs, and 15 sub-centres within the PHS.

\section{Participants}

Study participants were classified into two groups, namely, those who had received treatment and those who were untreated, never having accessed any treatment facility. Patients who had accessed mental health care services were either on medication currently or had discontinued them.

\section{Staff}

The survey staff comprised of 15 FSS and three MHPs (psychiatric social workers) anda research coordinator. The FSS were all hired locally from the region identifiedfor the survey, i.e., Thirumayam and Gandarvakottai taluks. They were primarily young individuals (age <35 years)and had completed, on average, 12 years ofeducation (high school graduates). Theywere trained in administering thesurvey questionnaire, recording data, and in the process of obtaining consent anddocumenting it. 


\section{Statistical analysis}

Statistical analysis was carried out involving descriptive and inferential statistics for comparing sociodemographic variables between the untreated and treated groups. Univariate logistic regression was carried out between education and the use of mental health care. All analyses were run on SPSS software version 16.

\section{RESULTS}

A total of 154539 eligible individuals were screened for SMD and identified 422 participants with SMD. Of the 422 patients with SMD recruited, $74 \%$ had accessed mental health care services at some point in time. Both groups had more patients in the 31- 45 age group, those who were married, and unemployed. Other sociodemographic factors can be found in Table 1.Between the groups, only education level was found to be significantly different $(\mathrm{p}<0.05)$.

Table 1. Comparison of socio-demographic variables between participants sought mental health care services and never sought mental health care services $(\mathrm{N}=422)$

\begin{tabular}{|c|c|c|c|}
\hline Variable & Untreated, N (\%) & Treated, N (\%) & Chi-Square/t-Test \\
\hline $\begin{array}{l}\text { Gender } \\
\text { Male } \\
\text { Female }\end{array}$ & $\begin{array}{l}45(40.9) \\
65(59.1)\end{array}$ & $\begin{array}{l}153(49) \\
159(51)\end{array}$ & 0.087 \\
\hline $\begin{array}{l}\text { Age } \\
0-15 \\
16-30 \\
31-45 \\
46-60 \\
>60\end{array}$ & $\begin{array}{l}0(0) \\
19(17.3) \\
48(43.6) \\
29(24.6) \\
14(12.7)\end{array}$ & $\begin{array}{l}1(0.3) \\
72(23.1) \\
142(45.5) \\
70(22.4) \\
27(8.7) \\
\end{array}$ & 0.461 \\
\hline $\begin{array}{l}\text { Education } \\
\text { Illiterate } \\
1-5 \text { std. } \\
6-10 \text { std. } \\
11-12 \text { std. } \\
\text { ITT/Diploma } \\
\text { College }\end{array}$ & $\begin{array}{l}51(46.4) \\
15(13.6) \\
35(31.8) \\
5(4.5) \\
1(0.9) \\
3(2.7) \\
\end{array}$ & $\begin{array}{l}96(30.8) \\
65(20.8) \\
104(33.3) \\
30(7.1) \\
1(0.3) \\
21(6.7) \\
\end{array}$ & 0.032 \\
\hline $\begin{array}{l}\text { Occupation } \\
\text { Unemployed } \\
\text { Owns land for agri. } \\
\text { Coolie } \\
\text { Govt. employee } \\
\text { Pvt. firm employee } \\
\text { Business } \\
\text { Student } \\
\text { Housewife } \\
\text { Retired } \\
\text { Others }\end{array}$ & $\begin{array}{l}38(34.5) \\
5(4.5) \\
25(22.7) \\
1(0.9) \\
1(0.9) \\
0(0) \\
0(0) \\
26(23.6) \\
4(3.6) \\
10(9.1) \\
\end{array}$ & $\begin{array}{l}119(38.1) \\
12(3.8) \\
60(19.2) \\
6(1.9) \\
7(2.2) \\
5(1.6) \\
1(0.3) \\
70(22.4) \\
11(3.5) \\
21(6.7) \\
\end{array}$ & 0.840 \\
\hline $\begin{array}{l}\text { Marital status } \\
\text { Married } \\
\text { Never married } \\
\text { Separated/divorced } \\
\text { Widow } \\
\end{array}$ & $\begin{array}{l}56(50.9) \\
24(21.8) \\
12(10.9)\end{array}$ & $\begin{array}{l}173(55.4) \\
66(21.2) \\
43(13.8) \\
18(16.4)\end{array}$ & $\begin{array}{l}0.251 \\
30(9.6)\end{array}$ \\
\hline $\begin{array}{l}\text { Religion } \\
\text { Hindu } \\
\text { Muslim } \\
\text { Christian } \\
\end{array}$ & $\begin{array}{l}108(98.2) \\
2(1.8) \\
0(0)\end{array}$ & $\begin{array}{l}289(92.6) \\
17(5.4) \\
6(1.9) \\
\end{array}$ & 0.092 \\
\hline
\end{tabular}


Among illness variables, age of onset, and GAFscores were not statistically different between twogroups (Table 2). Logistic regression depicted a positive correlation between education and access to mental health care services (Table 3).

Table 2: Comparison of illness variables (GAF score and age of onset) between participants sought mental health care services and never sought mental health care services $(N=422)$

\begin{tabular}{|l|c|c|c|}
\hline \multicolumn{1}{|c|}{ Variable } & Untreated, N (\%) & Treated, N (\%) & p-value \\
\hline GAF score & $42.7(15.9)$ & $44.5(15.9)$ & 0.710 \\
\hline Age of onset & $34.2(12.1)$ & $30.5(11.3)$ & 0.369 \\
\hline
\end{tabular}

Table 3: Univariate logistic regression of the socio-demographic variables associated with participants sought mental health care services and never sought mental health care services $(N=422)$

\begin{tabular}{|l|c|c|c|}
\hline \multicolumn{1}{|c|}{ Variable } & OR & $\mathbf{9 5 \%}$ CI & p \\
\hline Gender & 0.809 & $0.508-1.288$ & 0.372 \\
\hline Religion & 0.078 & $0.871-13.434$ & 0.078 \\
\hline Education & 0.602 & $0.379-0.959$ & 0.032 \\
\hline
\end{tabular}

\section{DISCUSSION}

This paper looked at factors related to access to mental health care services in a rural community in south India. Of all variables collected, only education level of the patients with SMD turned out to be significantly associated with seeking mental health care services. Those with higher education sought help earlier. Similar findings have been reported in studies worldwide., 21-24 Additionally, a study by Annequin et al., ${ }^{25}$ found that seeking psychiatric help was associated with high individual and parental education levels. Differences in various levels of education from illiteracy to college degrees were found, where more untreated than treated patients $(46.4 \%, 30.8 \%)$ were reported illiterate. Similar results have been published by Okasha et al., ${ }^{26}$ where illiteracy in Egyptian patients with psychotic disorders was correlated to a longer duration of untreated psychosis.

Education has been found to contribute to access to care through direct factors like poor mental health literacy and lack of awareness about the resources available. Awareness can involve psychoeducation, information about the medical condition and its severity, and the availability of resources such as hospitals, medical centres, and clinics. In many cases, awareness about mental illness or contact education with a patient can decrease stigma and intolerance. ${ }^{27}$ This can subsequently increase access or remove barriers to mental health care. Furthermore, a study by Harris et al. ${ }^{28}$ found that attitudinal or knowledge barriers to receiving care were more common than structural limitations like cost or distance. These results indicate that education in the form of awareness and mental health literacy could increase access to mental health care.

Lower education levels among patients in the community lead to various forms of alternative treatments such as magico- religious ones being accessed in place of medical care. However, in this study, the percentage of patients seeking alternative treatment was not found significant between treated and untreated groups. This reveals that a large portion of illiterate affected individuals remain untreated with longer DUPs and receive no form of treatment, medical or otherwise, for their severe mental disorder.

The social functioning of both groups of patients was similar, as reflected by the scores on the Global Assessment of Functioning (GAF) scale: untreated (42.7) and treated (44.5).This could be because they received only medication with no psychosocial interventions. However, a study by Ran et al.,7 found that GAF scores improved in the group treated only with antipsychotics. Thirthalli et al.,(2009) in India found higher disability among untreated than those treated with antipsychotics. Disability measured by Indian Disability Evaluation and Assessment Scale (IDEAS)correlated with the severity of illness symptoms. ${ }^{29}$ While, in general, higher severity of illness is correlated with poorer functioning, ${ }^{30}$ we were not able to substantiate this in our study. Studies have found that the functioning of untreated patients can be similar, if not better than treated patients due to the 
limitations of antipsychotic medication. Antipsychotic medications are ineffective or minimally effective for negative symptoms and cause extrapyramidal side effects. Similar results from a study by Jung et al., ${ }^{31}$ found that patients not on medication had significantly higher levels of functioning than patients on medication; they also found that longer duration without medication was associated with a higher level of general functioning. Our study found no significant difference in unemployment rates between untreated $(34.5 \%)$ and treated (38.1\%) groups. Aligned with our results, Ran et al., ${ }^{7}$ found that the untreated and treated patient groups with schizophrenia in their study both had difficulties in finding and maintaining work. This further illustrates that pharmacotherapy had little to no impact on the social functioning of patients in this and other relevant studies.

Another possibility could be that the patients who accessed mental health care services functioning did not improve after receiving medication as a sole treatment. The scores for both groups indicate serious impairment in social, occupational, or school functioning (GAF). Such low scores are prevalent among untreated patients but infrequently found in antipsychotic treated patients. Long term medication for patients with schizophrenia has been found to improve functioning up to a limit with no further improvement over time; patients not prescribed antipsychotic medication could function relatively well. ${ }^{32}$ Higher functioning and recovery are a result of psychosocial counselling, rehabilitation, and occupational therapy. ${ }^{33}$ These findings support the use of psychosocial interventions and rehabilitation as a method to improve impaired functioning in patients with schizophrenia. Numerous studies on improvement of functioning through interventions have found that psychosocial training or counselling can enhance a patients' social withdrawal and interpersonal skills. ${ }^{34}$ Psychosocial interventions like cognitive-behavioral therapy (CBT) and social skills training (SST) can improve negative symptoms and functioning in schizophrenia. ${ }^{35,36}$ Additionally, CBT has been found to improve negative symptoms and functioning by reducing asocial and defeatist beliefs. ${ }^{37}$

This study involved the use of multiple methods to collect data from the community and received confirmation on the status of treatment from patients themselves or their family members. The involvement of the psychiatric centre set up in the community could have influenced or impacted the number of patients accessing care during the study duration. This study did not take into consideration variables such as stigma, mental health literacy, attitudes to help-seeking, perceived need, or other commonly reported barriers to mental health service use when conducting the study or creating the study questionnaire. Such variables could be targeted for interventions to increase mental health service use. ${ }^{38}$

In the attempt to identify factors that facilitated help seeking from formal $\mathrm{MH}$ services, it was found that the level of education or literacy was a positive determinant of accessing care. Other variables did not seem to be significant. Similar GAF scores for both groups indicated that the treated group receiving medication did not have better functioning than the untreated group. This underscores the need for psychosocial interventions alongside pharmacotherapy to improve their social and cognitive functioning.

\section{Acknowledgement: None}

Source of funding: The study was funded by TATA Education Trust, India.

Conflict of interest: The authors have declared no conflict of interest with respect to the research, authorship,and/or publication of this article

\section{REFERENCES}

1 Wang PS, Angermeyer M, Borges G, et al. Delay and failure in treatment seeking after first onset of mental disorders in the World Health Organization's World Mental Health Survey Initiative. World Psychiatry. 2007;6(3):177-185

2 Black K, Peters L, Rui Q, et al. Duration of untreated psychosis predicts treatment outcome in an early psychosis program. Schizophrenia Research. 2001;47(2-3):215-222

3 Dell'Osso B, Glick ID, Baldwin DS, et al. Can Long-Term Outcomes Be Improved by Shortening the Duration of Untreated Illness in Psychiatric Disorders? A Conceptual Framework. Psychopathology. 2013;46(1):14-21

4 Perälä J, Suvisaari J, Saarni SI, et al. Lifetime Prevalence of Psychotic and Bipolar I Disorders in a General Population. Archives of General Psychiatry. 2007;64(1):19-28 
5 Kurihara T, Kato M, Reverger R, et al. Never-treated patients with schizophrenia in the developing country of Bali. Schizophrenia Research. 2005;79(2-3):307-313

6 Ran M-S, Chan CL-W, Chen EY-H, et al. Differences in mortality and suicidal behaviour between treated and never-treated people with schizophrenia in rural China. The British Journal of Psychiatry. 2009;195(2):126-131

7 Ran M-S, Weng X, Chan CL-W, et al. Different outcomes of never-treated and treated patients with schizophrenia: 14-year follow-up study in rural China. The British Journal of Psychiatry. 2015;207(6):495-500

8 Brenman NF, Luitel NP, Mall S, Jordans MJD. Demand and access to mental health services: a qualitative formative study in Nepal. BMC International Health and Human Rights. 2014;14:22

9 Dey M, Jorm AF. Social determinants of mental health service utilization in Switzerland. International Journal of Public Health. 2017;62(1):85-93

10 Gondek D, Kirkbride JB. Predictors of mental health help-seeking among polish people living the United Kingdom. BMC Health Services Research. 2018;18(1):693

11 Kular A, Perry BI, Brown L, et al. Stigma and access to care in first-episode psychosis. Early Intervention in Psychiatry. 2019;13(5):1208-1213

12 Padmavathi R, Rajkumar S, Srinivasan T. Schizophrenic patients who were never treated-a study in an Indian urban community. Psychological Medicine. 1998;28(5):1113-1117

13 Koschorke M, Padmavati R, Kumar S, et al. Experiences of stigma and discrimination faced by family caregivers of people with schizophrenia in India. Social Science \& Medicine. 2017;178:66-77

14 Corrigan PW, Druss BG, Perlick DA. The impact of mental illness stigma on seeking and participating in mental health care. Psychological Science in the Public Interest. 2014;15(2):37-70

15 Kishore J, Gupta A, Jiloha RC, Bantman P. Myths, beliefs and perceptions about mental disorders and healthseeking behavior in Delhi, India. Indian Journal of Psychiatry. 2011;53(4):324-329

16 Sethi BB, Sachdev S, Nag D. Sociocultural factors in the practice of psychiatry in India. American Journal of Psychotherapy. 1965;19(3):445-454

17 Grover S, Davuluri T, Chakrabarti S. Religion, spirituality, and schizophrenia: a review. Indian Journal of Psychological Medicine. 2014;36(2):119.

18 Mohr S, Brandt P-Y, Borras L, et al. Toward an integration of spirituality and religiousness into the psychosocial dimension of schizophrenia. American Journal of Psychiatry. 2006;163(11):1952-1959

19 Kapur R, Kapur M, Carstairs GM. Indian psychiatric survey schedule (IPSS). Social Psychiatry. 1974;9(2):71-76

20 Maxwell. Family interviewfor genetic studies. Bethesda,Maryland: Clinical Neurogenetics Branch, Intramural Research Program, NIMH. 1992

21 Bijl RV, Ravelli A. Psychiatric morbidity, service use, and need for care in the general population: results of The Netherlands Mental Health Survey and Incidence Study. American Journal of Public Health. 2000;90(4):602-607

22 Kovess-Masféty V, Saragoussi D, Sevilla-Dedieu C, et al. What makes people decide who to turn to when faced with a mental health problem? Results from a French survey. BMC Public Health. 2007;7(1):188

23 Parslow RA, Jorm AF. Who uses mental health services in Australia? An analysis of data from the National Survey of Mental Health and Wellbeing. Australia and New Zealand Journal of Psychiatry. 2000;34(6):997-1008

24 Schomerus G, Schwahn C, Holzinger A, et al. Evolution of public attitudes about mental illness: a systematic review and meta-analysis. Acta Psychiatrica Scandinavica. 2012;125(6):440-452 
25 Annequin M, Weill A, Thomas F, Chaix B. Environmental and individual characteristics associated with depressive disorders and mental health care use. Annals of Epidemiology. 2015;25(8):605-612

26 Okasha T, Zaki N, Meguid MAE, et al. Duration of untreated psychosis in an Egyptian sample: Sociodemographic and clinical variables. International Journal of Social Psychiatry. 2016;62(7):661-671

27 Stuart H, Chen S-P, Christie R, et al. Opening minds in Canada: background and rationale. The Canadian Journal of Psychiatry. 2014;59(Suppl. 1):8-12

28 Harris M, Baxter A, Reavley N, et al. Gender-related patterns and determinants of recent help-seeking for past-year affective, anxiety and substance use disorders: findings from a national epidemiological survey. Epidemiology and Psychiatric Sciences. 2016;25(6):548-561

29 Thirthalli J, Venkatesh BK, Kishorekumar KV, et al. Prospective comparison of course of disability in antipsychotic-treated and untreated schizophrenia patients. Acta Psychiatrica Scandinavica. 2009;119(3):209-217

30 Ertuğrul A, Uluğ B. The influence of neurocognitive deficits and symptoms on disability in schizophrenia. Acta Psychiatrica Scandinavica. 2002;105(3):196-201

31 Jung E, Wiesjahn $\mathrm{M}$, Wendt $\mathrm{H}$, et al. Symptoms, functioning and coping strategies in individuals with schizophrenia spectrum disorders who do not take antipsychotic medication: a comparative interview study. Psychological Medicine. 2016;46(10):2179-2188

32 Harrow M, Jobe TH, Faull RN, Yang J. A 20-Year multi-followup longitudinal study assessing whether antipsychotic medications contribute to work functioning in schizophrenia. Psychiatry Research. 2017;256:267-274

33 Kern RS, Glynn SM, Horan WP, Marder SR. Psychosocial Treatments to Promote Functional Recovery in Schizophrenia. Schizophrenia Bulletin. 2009;35(2):347-361

34 Dziwota E, Stepulak MZ, Włoszczak-Szubzda A, Olajossy M. Social functioning and the quality of life of patients diagnosed with schizophrenia. Annals of Agricultural and Environmental Medicine. 2018;25(1):50-55

35 Kurtz MM, Mueser KT. A meta-analysis of controlled research on social skills training for schizophrenia. Journal of Consulting and Clinical Psychology. 2008;76(3):491-504

36 Turner DT, van der Gaag M, et al. Psychological interventions for psychosis: a meta-analysis of comparative outcome studies. The American Journal of Psychiatry. 2014;171(5):523-538

37 Granholm E, Holden J, Link PC, McQuaid JR. Randomized clinical trial of cognitive behavioral social skills training for schizophrenia: Improvement in functioning and experiential negative symptoms. Journal of Consulting and Clinical Psychology. 2014;82(6):1173-1185

38 Bonabi H, Müller M, Ajdacic-Gross V, et al. Mental Health Literacy, Attitudes to Help Seeking, and Perceived Need as Predictors of Mental Health Service Use: A Longitudinal Study. Journal of Nervous and Mental Disease. 2016;204(4):321-324 